\title{
Potential role of miR-139-5p in cancer diagnosis, prognosis and therapy (Review)
}

\author{
LING-LI HUANG ${ }^{1}$, LING-WEI HUANG ${ }^{2}$, LEI WANG $^{3}$, BEN-DING TONG $^{3}$, QING WEI $^{3}$ and XUAN-SHENG DING ${ }^{1}$ \\ ${ }^{1}$ Department of Clinical Pharmacy, China Pharmaceutical University, Nanjing, Jiangsu 210009; \\ ${ }^{2}$ Key Laboratory for Space Biosciences and Biotechnology, Institute of Special Environmental Biophysics, \\ School of Life Sciences, Northwestern Polytechnical University, Xi'an, Shanxi 710072; \\ ${ }^{3}$ Department of Pharmacy, Jiangsu Cancer Hospital, Jiangsu Institute of Cancer Research, \\ Nanjing Medical University Affiliated Cancer Hospital, Nanjing, Jiangsu 210009, P.R. China
}

Received September 22, 2015; Accepted March 9, 2017

DOI: $10.3892 / 01.2017 .6351$

\begin{abstract}
MicroRNAs (miRNAs) are short non-coding RNAs that regulate the expression of protein-coding genes by partially binding to specific target sites of mRNAs. miRNAs perform important functions in complicated cellular biological processes and their abnormal expression is involved in various disorders, including cancer. Among the miRNAs, differential expression of miR-139-5p serves a significant role in tumorigenesis, metastasis and recurrence, thus suggesting that it may potentially be used as a promising biomarker for cancer diagnosis, prognosis and therapy. miR-139-5p is expected to serve as a biomarker to eventually be implemented in a clinical setting. In the present review, we focus on the importance of miR-139-5p in cancer, summarize the association between miR-139-5p expression level and diagnosis and prognosis, and discuss the potential therapeutic implications for the future.
\end{abstract}

\section{Contents}

1. Introduction

2. The biology of miR-139-5p

3. $\mathrm{miR}-139-5 \mathrm{p}$ in cancer diagnosis

4. miR-139-5p in cancer prognosis

5. $\mathrm{miR}-139-5 \mathrm{p}$ in cancer therapy

6. Conclusion and prospects

Correspondence to: Mr. Qing Wei, Department of Pharmacy, Jiangsu Cancer Hospital, Jiangsu Institute of Cancer Research, Nanjing Medical University Affiliated Cancer Hospital, 42 Baiziting, Nanjing, Jiangsu 210009, P.R. China

E-mail: jsschwq@sina.com

Mr. Xuan-Sheng Ding, Department of Clinical Pharmacy, China Pharmaceutical University, 24 Tongjiaxiang, Nanjing, Jiangsu 210009, P.R. China

E-mail: dxs0162@sina.com

Key words: microRNA, microRNA-139-5p, cancer, diagnosis, prognosis, therapy

\section{Introduction}

MicroRNAs (miRNAs), a class of small, highly conserved, non-coding RNAs of $\sim 22$ nucleotides, regulate the expression of protein-coding genes $(1,2)$. Lin-4 was initially discovered in Caenorhabditis elegans as a short non-coding RNA 20 years ago, and was observed to be essential to regulate developmental timing as a heterochronic switch gene (3). Then, miR-15a and miR-16-1 were demonstrated to be tumor suppressors, which was the first association between miRNAs deregulation and cancer (4). These observations contributed to the additional investigation of underlying mechanisms. In general, mature miRNAs negatively regulate their gene targets by binding to specific target sites within the 3'-untranslated region (UTR) of mRNAs for either translation repression or degradation (5). The interaction between miRNAs and mRNAs is complex: A single miRNA has multiple targets mRNAs, while a single mRNA has multiple conserved target sites for miRNA binding (6,7).

Previously, much attention was paid to these miRNAs in cancers (8-11). For instance, miR-27a is involved in activating the expression of $\mathrm{P}$-glycoprotein in ovarian cancer, and is therefore indirectly associated with drug susceptibility (8); miR-21 expression has a direct correlation with tumor invasion and metastasis (9); miR-139-5p serves a role in inhibiting tumor metastasis and progression in colorectal cancer (CRC) (10) and hepatocellular carcinoma (HCC) (11). This previous research has provided evidence of the association between miRNA abnormality and cancer. miRNAs perform important functions in diverse cellular biological processes, including proliferation, apoptosis, migration and invasion $(12,13)$.

miR-139-5p aberration is observed to be a frequent event in various disorders, including cancer. miR-139-5p was first characterized in neurodegeneration, and it was observed to be downregulated during the disease processes (5). Subsequently, miR-139-5p was identified to be responsible for cancer diagnosis, prognosis and therapy $(14,15)$. miR-139-5p has been investigated in various types of human cancer, including head and neck/oral cancer (HNOC) (7), breast cancer, gastric cancer (14), endometrial serous adenocarcinomas (16), CRC (17), bladder cancer (18), HCC (19), ovarian cancer (20), 
esophageal squamous cell carcinoma (ESCC) $(21,22)$, thyroid carcinomas (23), glioblastoma (24), basal cell carcinoma (25), renal cell carcinoma (RCC) (26), laryngeal squamous cell carcinoma (LSCC) (27), non-small cell lung cancer (28) and pancreatic cancer (29). Previous researches indicated that miR-139-5p is widely recognized as a tumor suppressor (16-29). Recently, however, miR-139-5p was identified to inhibit preadipocyte differentiation by targeting notch homolog 1 (NOTCH1), and insulin receptor substrate 1 (30), and to negatively regulate myoblast proliferation and differentiation by suppressing the Wnt1-mediated Wnt/ $\beta$-catenin signaling pathway (31). These results provided a potential therapeutic target of obesity, associated metabolic diseases (30) and myogenesis (31). In addition, miR-139-5p was demonstrated to exhibit an inverse correlation with receptor membrane component 1 (PGRMC1) in granulosa cells (32). All of these results indicate that miR-139-5p may be of crucial importance to cancer and other diseases.

miRNAs are stably expressed in human plasma and serum and easily measured in blood samples, making them good candidates for the non-invasive detection of disease; thus miR-139-5p may be a novel endogenous control for cancer $(33,34)$. Subsequently, the inherent regulatory function of miRNAs makes it likely that numerous miRNAs expressed in tumors may influence the biological behavior and clinical phenotype of the tumor (34). Furthermore, identification of miRNAs may be a more suitable and viable cost-effective alternative compared with other expensive commercial immunohistochemical profiling techniques (35). Considering these superiorities of miRNAs, miR-139-5p may be a promising biomarker in clinical practice.

A number of studies have identified that miR-139-5p serves a significant role in cancer biology, diagnosis, prognosis and therapy. As summarized in a previous review, miR-139-5p is involved in diverse biological processes and miRNA-regulated protein interaction networks (36). Increasing our understanding of the miRNA-mRNA regulatory mechanisms may also provide a novel individual-based therapeutic strategy (17). In the present review, we focus on the importance of miR-139-5p in cancer, summarize the association between miR-139-5p expression level and diagnosis and prognosis, and discuss the potential therapeutic implications for the future.

\section{The biology of miR-139-5p}

miR-139 is located within the second intron of the phosphodiesterase 2A gene on chromosome 11q13.4 (37,38), and miR-139-5p is a common type of mature miRNA generated from a miR-139 precursor (39). Similar to the biogenesis of other miRNAs, the miR-139 gene is transcribed by the RNA polymerase II to produce a long RNA molecule, primary-miR-139 (pri-miR-139) in the nucleus. The primary transcript is similar to protein-coding mRNAs with a 5'7-methylguanosine cap and poly-adenylated at the 3 'end. Subsequently, pri-miR-139 is processed into a hairpin-shaped stem-loop precursor (pre-miR-139) by the action of a RNase III endonucclease, Drosha and a cofactor, DGCR8/Pasha $(7,13)$. Pre-miR-139 is additionally cleaved in the cytoplasm by Dicer, a second RNase III endonuclease. Subsequently, two mature forms of miR-139 are formed: miR-139-3p processed from the 3'arm and miR-139-5p processed from the 5'arm of the stem loop sequence (39). Mature miRNAs are incorporated into the RNA-induced silencing complex (RISC) and guide the RISC to binding 3'-UTR of the target gene mRNA, leading to the degradation or translational inhibition of target mRNA $(13,40)$. Consistent with this, miR-139-5p target sites were observed to be located in the 3'-UTR of targeted mRNA in a number of previous studies $(26,39)$. However, it is notable that complementarity between the miRNA and its target site on the mRNA is partial. Therefore, there is the possibility for a single miRNA to regulate hundreds of potential targets $(5,41)$.

Notably, miR-139-5p and miR-139-3p expression profiles and levels vary in various types of cancer. For example, miR-139-5p and miR-139-3p were observed to be downregulated in tumor tissues compared with non-tumor tissues. However, miR-139-5p expression was gradually reduced during the development of CRC, while the expression of miR-139-3p demonstrated no significant difference in the various tumor stages of CRC (10). Furthermore, miR-139-3p was undetectable in HCC and adjacent non-tumor tissues (42). Abnormality of miR-139-5p is more common and significant than miR-139-3p expression in cancer, and demonstrates preferable research value and widely applicable prospects in clinical practice.

\section{3. miR-139-5p in cancer diagnosis}

Accurate and reliable results of diagnosis serve a critical role in guiding treatment and estimating prognosis. However, the present classification of certain types of cancer according to available clinical markers remains unreliable (43). As numerous tumors are not diagnosed until the disease is at the advanced stages, there is an urgent need to search for highly sensitive and minimally invasive biomarkers for diagnosis. Several years of experiments have demonstrated the potential role of miR-139-5p as a biomarker for screening and detection in tumors $(21,26,40,44)$. Clinicopathological analysis proved that downregulation of miR-139-5p was associated significantly with aggressive pathological features, including advanced tumor stages $(\mathrm{P}<0.001)$, presence of venous invasion $(\mathrm{P}=0.002)$ and tumor microsatellite formation $(\mathrm{P}=0.014)$, absence of tumor encapsulation $(\mathrm{P}=0.005)$, and poorer tumor cellular differentiation (Edmondson grade III/IV) $(\mathrm{P}=0.005)$ in HCC (42). Therefore, miR-139-5p could potentially be used as a screening tool to identify individuals who would benefit from additional diagnostic assessment.

Differential expression of miR-139-5p has been observed between cancer patients and healthy individuals. For example, miR-139-5p was reported to be expressed at lower levels in breast cancer samples vs. healthy controls $(35,44,45)$. Mammography, now as the standard screening tool worldwide for early breast cancer, has certain limitations (44). miR-139-5p may be useful to improve early detection of breast cancer. In addition, miR-139-5p expression was significantly reduced in bladder cancer cell lines compared with normal human bladder epithelium $(\mathrm{P}<0.0001)(18)$. Another study confirmed the downregulation of miR-139-5p in malignant bladder tissue samples $(\mathrm{P}<0.0001)(46)$.

ESCC is generally diagnosed at the terminal stages. Reduced levels of miR-139-5p at this stage of ESCC imply a 
latent capacity to improve early diagnosis (22). Conditional logistic regression analysis has demonstrated a close correlation between reduced miR-139-5p expression and increased risk for esophageal cancer (odds ratio=2.024) (21). miR-139-5p expression levels were significantly depleted in patients with lymph node metastasis compared to those without lymph node metastasis $(\mathrm{P}=0.040)(21)$, which may indicate be value for differential diagnosis. Furthermore, miR-139 expression demonstrated a significant decrease during HCC progression from normal liver to late-stage $\mathrm{HCC}$ when samples were categorized into 5 groups: Normal livers and those with no background liver disease, non-tumorous livers with chronic hepatitis, non-tumorous livers with cirrhosis, early HCC, and advanced HCC (42). Additionally, the expression of miR-139 was reduced along with the progression of primary to metastatic LSCC (27). Thus, miR-139-5p may be a novel marker to reflect the development of tumors.

miR-139-5p is involved in breast cancer, bladder cancer, ESCC, HCC, LSCC and others (20-23,29); it is supposed to be used for molecular diagnosis of these forms (29). miR-139-5p may be helpful to decrease misdiagnosis rates and judge correctly the stage of cancer according to the reduced extent of miR-139-5p expression. More notably, quantitative polymerase chain reaction molecular testing is sensitive and powerful (35), and exosome-based diagnostic techniques have the potential for high reproducibility and require only a blood sampe, without any damage to patients (47). Besides, miR-139-5p appears to be a feasible and inexpensive marker for cancer diagnosis.

\section{4. miR-139-5p in cancer prognosis}

Enhancement of migration and invasion, as phenotypes of cell transformation, are involved in the process of metastasis of cancer cells (48), thus making it essential for improved stratification of cancer patients to predict disease recurrence risk and to guide therapy (17). Pathological features including tumor size, stage, grade, lymph-node metastasis, vascular invasion and metastasis are prognotic factors, but do not reflect the status of tumor progression and treatment efficacy (49). Therefore, a number of studies have indicated that the expression of miR-139 may act as an independent prognostic factor that is significantly associated with overall survival rates of cancer patients.

To investigate the mechanism by which miR-139-5p exerts anti-metastatic functions in cancer, the online resources miRanda (http://www.microrna.org/microrna/home.do), TargetScan (http://www.targetscan.org//vert_50/seedmatch. html), and PicTar (http://pictar.mdc-berlin.de/) were used to predict potential miR-139 targets $(48,50)$. miR-139-5p possible targets, including topoisomerase II $\alpha$ (TOP2a), insulin-like growth factor 1 receptor (IGF-1R), Rho-kinase 2 (ROCK2), are involved in cancer progression and metastasis.

There is evidence that loss of miR-139-5p expression indirectly increases cell proliferation and inhibits apoptosis (Fig. 1), and exerts positive effects on the occurrence and progression of tumors. A previous study indicated that IGF-1R, ROCK2 and Ras-related protein $1 \mathrm{~B}$ (RAP1B) are involved in the same mechanism of miRNA-mediated regulation, regulating each other in a miR-139-5p-dependent manner in CRC (38).
Overexpression of RAP1B, tetraspanin 5 (TSPAN5) and forkhead box protein O1in (FOXO1A) CRC may result from the underexpression of miR-139 (50). As a critical mediator of the miR-139 anti-proliferative effect in cell lines, RAP1B encodes a member of the Ras super family of G-proteins (50) and negatively accommodates the activity of p38 mitogen-activate protein kinase signaling (51). miR-139-5p is able to cause aberrant cell cycle arrest in $\mathrm{G} 0 / \mathrm{G} 1$ phase $(\mathrm{P}<0.01)$, with upregulation of two cyclin dependent kinase (CDK) inhibitors, $\mathrm{p} 21^{\text {Cip1/Waf1 }}$ and $\mathrm{p} 27^{\mathrm{Kip} 1}$ (52), which inhibit the activity of cyclin D-CDK2/4 complexes, therefore inhibiting E2F transcriptional activity and cell cycle progression to S-phase (53). Apoptosis is concomitant with cell cycle arrest induced by miR-139-5p. The extrinsic apoptosis pathway is initiated by the binding of extracellular death ligands, including tumor necrosis factor $\alpha$, to transmembrane death receptors, inducing aggregation of adaptor proteins, including Fas-associated death domain protein, which in turn promotes activation of apoptosis executors caspase-8, caspase- 3 and caspase-7 to initiate the proteolytic cleavage of nuclear poly (ADP-ribose) polymerase, thus causing loss of DNA repair, cellular disassembly and apoptosis (52). miR-139-5p was identified as a tumor suppressor inhibiting cell proliferation, migration and invasion in lung cancer, partially via downregulating IGF-1R expression (28). Positive correlations between IGF-IR/matrix metallopeptidase-2 (MMP-2) expression and negative correlations between MMP-2/miR-139 expression were also observed in primary CRC tissues, indicating that miR-139 may inhibit IGF-IR expression and downregulate MMP-2 synthesis via MEK/extracellular signal-regulated kinase (ERK)/nuclear factor (NF) $-\kappa B$ signaling (10).

Overexpression of miR-139-5p is able to inhibit cell migration and invasion in vitro and metastasis in vivo. Fig. 2 summarizes the signaling pathways of miR-139 that suppress cell migration and invasion. Endogenous autocrine motility factor receptor (AMFR) and NOTCH1 protein levels were decreased in miR-139-5p-overexpressing CRC cells and could be restored in miR-139-5p-depleted cells (54). Autocrine motility factor (AMF) has been demonstrated to stimulate endothelial motility and to function as an angiogenic factor (55). The ligand of AMF, AMFR, also known as gp78, is able to target itself for proteasomal degradation in a RING finger- and MmUBC7-dependent manner (55), resulting in signaling cascades relying on protein kinase $\mathrm{C}$ and activating Ras homolog (Rho)-like GTPase, Rho gene family, member A and Ras-related $\mathrm{C} 3$ botulinum toxin substrate 1, thereby enhancing cell motility (56). Activation of AMFR by AMF has been demonstrated to alter cell adhesion, motility and angiogenesis (57). NOTCH1 was observed to be directly regulated by $\mathrm{miR}-139-5 \mathrm{p}$ at the post-transcriptional level and promoted CRC invasion; in addition, significant association was observed between NOTCH1 expression and survival (54). In accordance with previous findings, ectopic expression of miR-139-5p significantly suppressed oncogenic NOTCH1 downstream effectors, including hairy and enhancer of split-1, cyclin D1 and Fas-associated protein with death domain-like apoptosis regulator transcription (52). Furthermore, miR-139-5p inhibited cellular migration and invasion through the inhibition of MMP7 and MMP9 (52). miR-139 was inferred to be a key tumor suppressor in early CRC development by targeting 


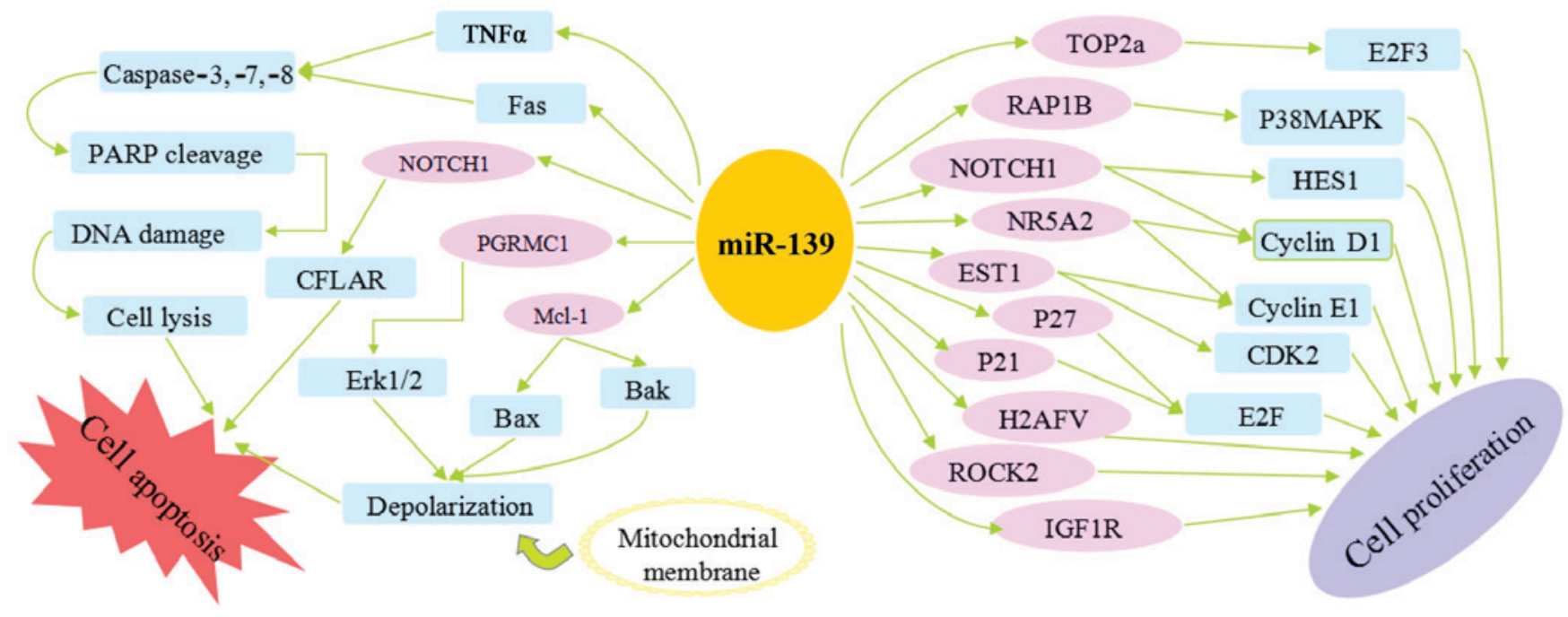

Figure 1. Regulation of cell proliferation and apoptosis by microRNA-139.

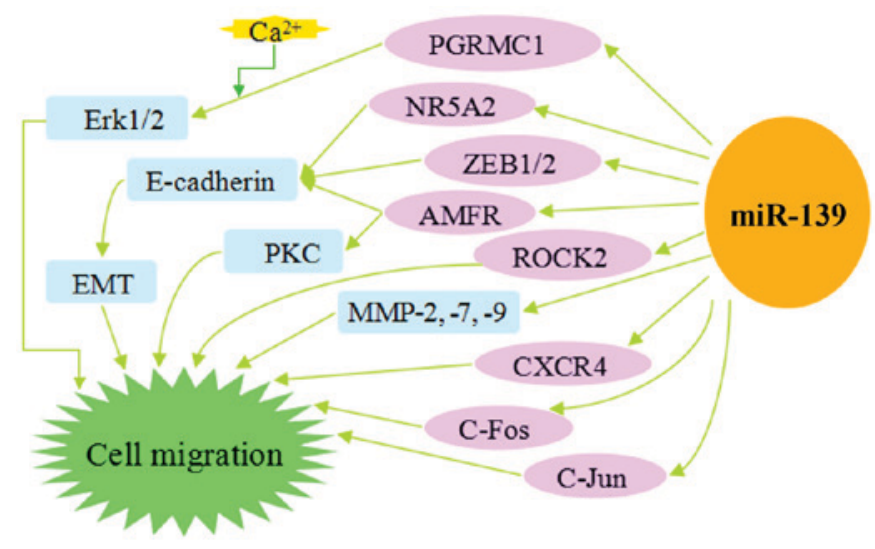

Figure 2. MicroRNA-139 as an inhibitor of cell migration and invasion.

ETS1 (58). Therefore, miR-139-5p has the possibility to serve as a molecular therapeutic target and prognostic marker.

Expression levels of miR-139-5p in HCC tissues and cell lines were significantly reduced compared to control groups in a number of previous studies $(59,60)$. A previous study demonstrated that knockdown of zeste homolog 2 (EZH2) suppressed HCC motility in vitro and pulmonary metastasis in a nude mouse model, and EZH2 was hypothesized to promote cancer metastasis through tumor suppressor miR-139-5p by effectively and extensively regulating a variety of signaling pathways, particularly those involved in cell motility and metastasis (59). Another previous study revealed that ROCK 2 served a significant role in HCC migration, invasion and progression (60). Furthermore, miR-139 was identified to suppress HCC cell migration in vitro and pulmonary metastasis in vivo by targeting the prometastatic protein ROCK2 in the Rho-dependent actin cytoskeleton remodeling signaling pathway (42). Mechanistic investigation revealed that overexpression of miR-139 inhibits cell proliferation and invasion through suppressing $\beta$-catenin/T-cell factor-4 (TCF-4) transcriptional activity, lessening the relative expression of $\beta$-catenin, cyclin D1, c-Myc, MMP-2 and MMP-9 (11). miR-139-5p was confirmed to negatively regulate Zinc finger E-box binding homeobox1 (ZEB1) and ZEB2 expression (61). ZEB1 and ZEB2 contain two $\mathrm{C} 2 \mathrm{H} 2$-type zinc fingers that mediate their binding to paired CAGGTA/GE-box-like promoter elements, and function as transcriptional repressors (62). These repressors induce epithelial mesenchymal transition by suppressing the expression of E-cadherin and contribute to the progression of malignant cancer (63).

Activated protein-1, a heterodimeric transcription activator, is composed of c-Jun and c-Fos to regulate the expression of genes essential for cell proliferation and differentiation (48). Jun was reported to be in the center of target-pathway and target-function networks (64). A previous study indicated that miR-139 was able to inhibit Jun expression by targeting a conserved site on its $3^{\prime}$-UTR, and in turn Jun was able to induce miR-139 expression in a dose-dependent manner via a distant upstream regulatory element, thus forming a negative feedback loop to fine-tune tissue homeostasis (64). c-Fos has also been reported to be an oncogene involved in HCC metastasis $(65,66)$. In vitro cell migration analysis demonstrated that depletion of c-Fos or overexpression of miR-139 in HCC cell sublines transfected with miR-139 mimics reduced cell migration, whereas overexpression of c-Fos or depletion of miR-139 in HCC cell sublines transfected with miR-139 inhibitor increased cell migration (67). These findings imply that miR-139-5p is closely associated with the development and metastasis of malignant tumors, therefore it may be an independent prognostic predictor for HCC.

TOP2a, known as a gene encoding an enzyme involved in transforming DNA topology, including chromosome condensation, chromatid separation and the relief of torsional stress occurring in transcription and replication (20), was identified to be a target of miR-139-5p in breast cancer, and may mediate transcriptional activation function of $\mathrm{E} 2 \mathrm{~F} 3$ to control the rate of cell proliferation (68). H2A histone family member V, HRAS, NF-кB1, phosphatidylinositol-4,5-bisphosphate 3-kinase catalytic subunit $\alpha, \mathrm{RAF}$ and RhoT1 were also shown to be targets of miR-139-5p underlying cellular processes involved in metastasis in breast cancer $(35,69)$. A significant functional role has been suggested for miR-139-5p in breast cancer cell 
Table I. Abnormal expression and target genes of miR-139-5p in different types of cancers.

\begin{tabular}{|c|c|c|c|}
\hline Cancer type & $\begin{array}{l}\text { miR-139-5p } \\
\text { expression }\end{array}$ & Target gene & (Refs.) \\
\hline Head and neck/oral cancer & Downregulated & Unknown & $(6,7)$ \\
\hline Breast cancer & Downregulated & $\begin{array}{l}\text { TOP2a, H2AFV, HRAS, RAF, NFKB1, } \\
\text { PIK3CA, RHOT1 }\end{array}$ & $(20,35,69)$ \\
\hline Gastric cancer & Downregulated & CXCR4, c-Jun & (79) \\
\hline $\begin{array}{l}\text { Endometrial serous } \\
\text { adenocarcinoma }\end{array}$ & Downregulated & Unknown & $(16)$ \\
\hline Colorectal cancer & Downregulated & $\begin{array}{l}\text { IGF-1R, ROCK2, RAP1B, TSPAN5, FOXO1A, } \\
\text { TNF } \alpha \text {, Fas, AMFR, NOTCH1, ETS1 }\end{array}$ & $(38,48,50,52,53,56)$ \\
\hline Bladder cancer & Downregulated & Unknown & $(18)$ \\
\hline Hepatocellular carcinoma & Downregulated & EZH2, ROCK2, ZEB1/2, c-Fos & $(57-59,63-65)$ \\
\hline Ovarian cancer & Downregulated & TOP2a, RACGAP1, DNAH9, E2F3 & $(20)$ \\
\hline $\begin{array}{l}\text { Esophageal squamous } \\
\text { cell carcinoma }\end{array}$ & Downregulated & NR5A2 & $(21,22)$ \\
\hline Thyroid carcinoma & Downregulated & Unknown & $(23)$ \\
\hline Glioblastoma & Downregulated & Mcl-1 & $(24)$ \\
\hline Basal cell carcinoma & Downregulated & Unknown & $(25)$ \\
\hline Renal cell carcinoma & Downregulated & Unknown & (26) \\
\hline Lung squamous cell carcinoma & Downregulated & CXCR4 & (27) \\
\hline Non-small cell lung cancer & Downregulated & IGF-1R & $(28)$ \\
\hline Pancreatic cancer & Upregulated & Unknown & (29) \\
\hline Granulosa cell tumor & Upregulated & PGRMC1 & $(32)$ \\
\hline
\end{tabular}

miR, microRNA.

motility and invasion, and it has potential to be used as a prognostic marker for aggressive forms of breast cancer (69).

miR-139-5p exerts a growth- and invasiveness-suppressing function in human ESCCs by targeting the oncogenic nuclear receptor subfamily 5 group A member 2 (NR5A2) (21). NR5A2, also known as liver receptor homolog-1, enhances cell cycle progression through the G1 phase and cell proliferation by inducing the expression of cyclins D1 and E1, and prevents cells from apoptosis $(70,71)$. A previous study demonstrated that its overexpression resulted in the post-translational truncation of E-cadherin and increased expression of MMP-9 (72), consequently contributing to cancer motility and invasion.

Notably, hyaluronic acid has been reported to downregulate miR-139-5p expression via histone deacetylation (32), and hyaluronic acid is involved in cell migration, proliferation, differentiation and apoptosis $(73,74)$. miR-139-5p was demonstrated to promote apoptosis and inhibit functioning of granulosa cells by regulating the expression of progesterone receptor membrane component (PGRMC) 1 (32), which is able to participate in $\mathrm{P} 4$ signaling transduction in the reproductive system and mediates the anti-apoptotic effects of $\mathrm{P} 4$ on granulosa cells (75). Furthermore, it was reported that PGRMC1 regulates cell viability through increasing protein kinase $G$ activity and suppressing ERK1/2 activity, as well as decreasing intracellular free calcium levels (75) and activating enzymatic activity of cytochrome $\mathrm{P} 450$ involved in sterol biosynthesis (76).

By contrast, miR-139-5p expression was upregulated by $>20$-fold in pancreatic cancer endothelial cells compared with normal endothelial cells, which may be due to cell type-specific differences (29). In addition, miR-139 demonstrated a positive impact on endothelial cell migration and vasculature formation during angiogenesis (29). Angiogenesis is an important step in the development of tumors and is necessary for primary tumor growth, invasion and metastasis. miR-139 is of potential therapeutic value for suppression of tumor invasion and metastasis by inhibiting angiogenesis $(77,78)$. The study revealed that miR-139-5p overexpression may assist with the spread of cancer, while others have demonstrated its inhibition of expansion and metastasis (29).

Univariate analysis demonstrated that reduced expression of miR-139-5p was significantly correlated with shorter overall survival time (log-rank test, $\mathrm{P}=0.043$ ) in patients with endometrial serous adenocarcinoma (16). Additional studies demonstrated that miR-139 reduced expression of C-X-C chemokine receptor type 4 (CXCR4), and CXCR4 was directly targeted by miR-139 in LSCC (27) and gastric cancer (79). miR-139-5p is also associated with metastasis and prognosis of clear cell RCC (26). However, additional research in this field is required to investigate the mechanisms and clinical potential of miR-139-5p.

The data discussed in this section indicate the tumorsuppressive role of miR-139-5p reflecting the status of tumor growth and spread; therefore, miR-139-5p may be a possible therapeutic target and prognosticator of cancer. Based on the results of previous studies, it appears that miR-139-5p serves as a pivotal mediator in regulation of progression and metastasis. 
miR-139-5p may have substantial clinical significance and implications in the clinical setting, but additional research is required to indicate the critical role of miR-139-5p in the prognosis of various types of cancer.

\section{5. miR-139-5p in cancer therapy}

Availability of potent prognostic and predictive factors serves a crucial function for clinical decisions on cancer treatment, guiding patient decision-making and the selection of a therapeutic schedule (80). miR-139-5p may serve as a tumor suppressor and is significantly downregulated in various types of cancer, including HNOC (7), breast cancer $(45,81)$ and gastric cancer (79). Furthermore, the miR-139-5p expression signature has been reported to be associated with the clinical outcome of cancer patients $(82,83)$, and may serve as a therapeutic target for novel strategies for prevention and therapy.

A study identified that Mcl-1 is one of meaningful targets of miR-139 in glioblastoma (24). Mcl-1 serves as an anti-apoptotic factor, preserves mitochondrial membrane integrity by binding to mitochondrial porin channels (82) and protects mitochondria by sequestering proapoptotic B-cell lymphoma 2 (Bcl-2) family members, Bcl-2 associated $\mathrm{X}$, apoptosis regulator and Bcl-2 antagonist/killer (84), thus inhibiting initiation of apoptosis and conferring a survival advantage to tumor cells. In addition, it has been reported that miR-139 suppresses proliferation and enhances apoptosis in coordination with an anticancer drug temozolomide via negative regulation of Mcl-1 in glioma (24). Notably, Mcl-1 has also been reported to mediate resistance to rituximab in chronic lymphocytic leukemia (83) and enhance the efficacy of rituximab therapy (82), further supporting Mcl-1 as a viable therapeutic target for the treatment of cancer.

As a recombinant monoclonal antibody to human epidermal growth factor (HER2), trastuzumab is among the most successful therapeutics for metastatic breast cancer (85). Bao et al (79) demonstrated in gastric cancer that trastuzumab treatment restores the expression of a CXCR4-targeted miRNA, miR-139, which is suppressed by upstream HER2 signaling.

The results in two clinical studies revealed that miR-139 was significantly downregulated in early cancer pathological stages compared with adjacent non-cancerous tissues, and it remained at a very low expression level in advanced pathological stages $(58,86)$. Subsequently, it was indicated that miR-139 was able to directly suppress ETS1 activity via the conserved binding site (58). ETS1 is an oncogenic transcription factor, and is able to promote cell cycle G1/S transition by transcriptionally upregulating the cyclin $\mathrm{E}$ and $\mathrm{CDK} 2$ genes, the master regulators of G1/S-phase transition (87).

Whether Mcl-1, CXCR4 and ETS1 are involved in sensitization of cancer cells to anticancer drugs remains to be determined. miR-139-5p targeting represents a plausible therapeutic approach (Table I). Increasing the level of miR-139-5p in tumor cells using chemically synthesized oligonucleotides or artificially engineered expression vectors may suppress cancer cell proliferation through the regulation of endogenous targets of miR-139-5p (50). Furthermore, apoptosis resistance is an important characteristic of tumor cells (24). Consequently, extrinsic induction of apoptosis has been considered to be an important antitumor mechanism. Therapeutic interventions that simultaneously target these targets, such as Mcl-1, CXCR4 and ETS1, and restore tumor suppressor miR-139-5p may lead to improved treatments for aggressive malignancies. In addition, considerable studies of the underlying molecular mechanisms will be necessary to additionally investigate putative miR-139-5p targets and elucidate the role of miR-139-5p as a tumor inhibitor.

\section{Conclusion and prospects}

In the present review, we focused on the differential expression of miR-139-5p in numerous types of cancer and its potential role in cancer diagnosis, prognosis and therapy. Downregulation of miR-139-5p may be measured and used to accurately assess cancer condition, leading to evaluation of prognosis and guiding of appropriate therapy. Restoring the expression of miR-139-5p exerts tumor suppression mediated by targets of miR-139-5p through regulating proliferation, apoptosis, migration and invasion of cancer cells. However, it should be noted that loss of expression of miR-139-5p may prevent cancerous tumor growth by halting the formation of new blood vessels needed for tumor growth and extension. It may be hypothesized that miR-139-5p can serve as a biomarker to be implemented in a clinical setting. Though research into miR-139-5p has provided insight into our knowledge of human cancer, the molecular mechanisms underlying metastatic migration and invasion are only partially understood and require additional investigation.

\section{Acknowledgements}

The authors would like to acknowledge the pharmacologists of Jiangsu Cancer Hospital, Jiangsu Institute of Cancer Research, Nanjing Medical University Affiliated Cancer Hospital (Nanjing, China), for their helpful advice and comments on the manuscript.

\section{References}

1. Bartel DP: MicroRNAs: Genomics, biogenesis, mechanism, and function. Cell 116: 281-297, 2004.

2. Calin GA and Croce CM: MicroRNA signatures in human cancers. Nat Rev Cancer 6: 857-866, 2006.

3. Lee RC, Feinbaum RL and Ambros V: The C. Elegans heterochronic gene lin-4 encodes small RNAs with antisense complementarity to lin-14. Cell 75: 843-854, 1993.

4. Calin GA, Dumitru CD, Shimizu M, Bichi R, Zupo S, Noch E, Aldler H, Rattan S, Keating M, Rai K, et al: Frequent deletions and down-regulation of micro-RNA genes miR15 and miR16 at 13 q14 in chronic lymphocytic leukemia. Proc Natl Acad Sci USA 99: 15524-15529, 2002.

5. Saba R, Goodman CD, Huzarewich RL, Robertson C and Booth SA: A miRNA signature of prion induced neurodegeneration. PLoS One 3: e3652, 2008.

6. Lewis BP, Burge CB and Bartel DP: Conserved seed pairing, often flanked by adenosines, indicates that thousands of human genes are microRNA targets. Cell 120: 15-20, 2005.

7. Liu X, Chen Z, Yu J, Xia J and Zhou X: MicroRNA profiling and head and neck cancer. Comp Funct Genomics: 837514, 2009.

8. Zhu H, Wu H, Liu X, Evans BR, Medina DJ, Liu CG and Yang JM: Role of MicroRNA miR-27a and miR-451 in the regulation of MDR1/P-glycoprotein expression in human cancer cells. Biochem Pharmacol 76: 582-588, 2008.

9. Li T, Leong MH,Harms B, Kennedy G and Chen L: MicroRNA-21 as a potential colon and rectal cancer biomarker. World J Gastroenterol 19: 5615-5621, 2013. 
10. Shen K, Liang Q, Xu K, Cui D, Jiang L, Yin P, Lu Y, Li Q and Liu J: MiR-139 inhibits invasion and metastasis of colorectal cancer by targeting the type I insulin-like growth factor receptor. Biochem Pharmacol 84: 320-330, 2012.

11. Gu W, Li X and Wang J: miR-139 regulates the proliferation and invasion of hepatocellular carcinoma through the WNT/TCF-4 pathway. Oncol Rep 31: 397-404, 2014.

12. Bar M, Wyman SK, Fritz BR, Qi J, Garg KS, Parkin RK, Kroh EM, Bendoraite A, Mitchell PS, Nelson AM, et al: MicroRNA discovery and profiling in human embryonic stem cells by deep sequencing of small RNA libraries. Stem Cells 26: 2496-2505, 2008.

13. Croce CM: Causes and consequences of microRNA dysregulation in cancer. Nat Rev Genet 10: 704-714, 2009

14. Guo J, Miao Y, Xiao B, Huan R, Jiang Z, Meng D and Wang Y: Differential expression of microRNA species in human gastric cancer versus non-tumorous tissues. J Gastroenterol Hepatol 24: 652-657, 2009.

15. Mascaux C, Laes JF, Anthoine G, Haller A, Ninane V, Burny A and Sculier JP: Evolution of microRNA expression during human bronchial squamous carcinogenesis. Eur Respir J 33 352-359, 2009.

16. Hiroki E, Akahira J, Suzuki F, Nagase S, Ito K, Suzuki T, Sasano H and Yaegashi N: Changes in microRNA expression levels correlate with clinicopathological features and prognoses in endometrial serous adenocarcinomas. Cancer Sci 101: 241-249, 2010.

17. Chang KH, Miller N, Kheirelseid EA, Lemetre C, Ball GR, Smith MJ, Regan M, McAnena OJ and Kerin MJ: MicroRNA signature analysis in colorectal cancer: Identification of expression profiles in stage II tumors associated with aggressive disease. Int J Colorectal Dis 26: 1415-1422, 2011.

18. Yoshino H, Chiyomaru T, Enokida H, Kawakami K, Tatarano $\mathrm{S}$, Nishiyama $\mathrm{K}$, Nohata $\mathrm{N}$, Seki $\mathrm{N}$ and Nakagawa $\mathrm{M}$ : The tumour-suppressive function of miR-1 and miR-133a targeting TAGLN2 in bladder cancer. Br J Cancer 104: 808-818, 2011.

19. Huang Y, Chen HC, Chiang CW, Yeh CT, Chen SJ and Chou CK: Identification of a two-layer regulatory network of proliferation-related microRNAs in hepatoma cells. Nucleic Acids Res 40: 10478-10493, 2012.

20. Miles GD, Seiler M, Rodriguez L, Rajagopal G and Bhanot G: Identifying microRNA/mRNA dysregulations in ovarian cancer. BMC Res Notes 5: 164, 2012.

21. Liu R, Yang M, Meng Y, Liao J, Sheng J, Pu Y, Yin L and Kim SJ: Tumor-suppressive function of miR-139-5p in esophageal squamous cell carcinoma. PLoS One 8: e77068, 2013.

22. Yang M, Liu R, Sheng J, Liao J, Wang Y, Pan E, Guo W, Pu Y and Yin L: Differential expression profiles of microRNAs as potential biomarkers for the early diagnosis of esophageal squamous cell carcinoma. Oncol Rep 29: 169-176, 2013

23. Dettmer MS, Perren A, Moch H, Komminoth P, Nikiforov YE and Nikiforova MN: MicroRNA profile of poorly differentiated thyroid carcinomas: New diagnostic and prognostic insights J Mol Endocrinol 52: 181-189, 2014

24. Li RY, Chen LC, Zhang HY, Du WZ, Feng Y, Wang HB, Wen JQ, Liu X, Li XF, Sun Y, et al: MiR-139 inhibits Mcl-1 expression and potentiates TMZ-induced apoptosis in glioma. CNS Neurosci Ther 19: 477-483, 2013

25. Sand M, Skrygan M, Sand D, Georgas D, Hahn SA, Gambichler T, Altmeyer P and Bechara FG: Expression of microRNAs in basal cell carcinoma. Br J Dermatol 167: 847-855, 2012.

26. Wu X, Weng L, Li X, Guo C, Pal SK, Jin JM, Li Y, Nelson RA, $\mathrm{Mu} \mathrm{B}$, Onami SH, et al: Identification of a 4-microRNA signature for clear cell renal cell carcinoma metastasis and prognosis. PLoS One 7: e35661, 2012.

27. Luo HN, Wang ZH, Sheng Y, Zhang Q, Yan J, Hou J, Zhu K, Cheng Y, Xu YL, Zhang XH, et al: MiR-139 targets CXCR4 and inhibits the proliferation and metastasis of laryngeal squamous carcinoma cells. Med Oncol 31: 789, 2014.

28. Xu W, Hang M, Yuan CY, Wu FL, Chen SB and Xue K: MicroRNA-139-5p inhibits cell proliferation and invasion by targeting insulin-like growth factor 1 receptor in human non-small cell lung cancer. Int J Clin Exp Pathol 8: 3864-3870, 2015.

29. Li L, Li B, Chen D, Liu L, Huang C, Lu Z, Lun L and Wan X: miR-139 and miR-200c regulate pancreatic cancer endothelial cell migration and angiogenesis. Oncol Rep 34: 51-58, 2015.

30. Mi L, Chen Y, Zheng X, Li Y, Zhang Q, Mo D and Yang G: MicroRNA-139-5p suppresses 3T3-L1 preadipocyte differentiation through notch and IRS1/PI3K/Akt insulin signaling pathways. J Cell Biochem 116: 1195-1204, 2015.
31. Mi L, Li Y, Zhang Q, Zhao C, Peng Y, Yang G and Zheng X: MicroRNA-139-5p regulates $\mathrm{C} 2 \mathrm{C} 12$ cell myogenesis through blocking Wnt/ $\beta$-catenin signaling pathway. Biochem Cell Biol 93: 8-15, 2015.

32. Zhao G, Zhou X, Fang T, Hou Y and Hu Y: Hyaluronic acid promotes the expression of progesterone receptor membrane component 1 via epigenetic silencing of miR-139-5p in human and rat granulosa cells. Biol Reprod 91: 116, 2014.

33. MacLellan SA, MacAulay C, Lam S and Garnis C: Pre-profiling factors influencing serum microRNA levels. BMC Clin Pathol 14: 27, 2014.

34. Mitchell PS, Parkin RK, Kroh EM, Fritz BR, Wyman SK, Pogosova-Agadjanyan EL, Peterson A, Noteboom J, O'Briant KC, Allen A, et al: Circulating microRNAs as stable blood-based markers for cancer detection. Proc Natl Acad Sci USA 105: 10513-10518, 2008.

35. Cava C, Bertoli G, Ripamonti M, Mauri G, Zoppis I, Della Rosa PA, Gilardi MC and Castiglioni I: Integration of mRNA expression profile, copy number alterations, and microRNA expression levels in breast cancer to improve grade definition. PLoS One 9: e97681, 2014

36. Zhang HD, Jiang LH, Sun DW, Li J and Tang JH: MiR-139-5p: Promising biomarker for cancer. Tumour Biol 36: 1355-1365, 2015.

37. Corbetta S, Vaira V, Guarnieri V, Scillitani A, Eller-Vainicher C, Ferrero S, Vicentini L, Chiodini I, Bisceglia M, Beck-Peccoz P, et al: Differential expression of microRNAs in human parathyroid carcinomas compared with normal parathyroid tissue. Endocr Relat Cancer 17: 135-146, 2010.

38. Shen K, Mao R, Ma L, Li Y, Qiu Y, Cui D, Le V, Yin P, Ni L and Liu J: Post-transcriptional regulation of the tumor suppressor miR-139-5p and a network of miR-139-5p-mediated mRNA interactions in colorectal cancer. FEBS J 281: 3609-3624, 2014.

39. Tombol Z, Eder K, Kovács A, Szabó PM, Kulka J, Likó I, Zalatnai A, Rácz G, Tóth M, Patócs A, et al: MicroRNA expression profiling in benign (sporadic and hereditary) and recurring adrenal pheochromocytomas. Mod Pathol 23: 1583-1595, 2010.

40. Qin C, Huang RY and Wang ZX: Potential role of miR-100 in cancer diagnosis, prognosis, and therapy. Tumour Biol 36: 1403-1409, 2015

41. Gu DN, Huang Q and Tian L: The molecular mechanisms and therapeutic potential of microRNA-7 in cancer. Expert Opin Ther Targets 19: 415-426, 2015.

42. Wong CC, Wong CM, Tung EK, Au SL, Lee JM, Poon RT, Man K and Ng IO: The microRNA miR-139 suppresses metastasis and progression of hepatocellular carcinoma by down-regulating Rho-kinase 2. Gastroenterology 140: 322-331, 2011.

43. Aghagolzadeh P and Radpour R: New trends in molecular and cellular biomarker discovery for colorectal cancer. World J Gastroenterol 22: 5678-5693, 2016.

44. Kodahl AR, Lyng MB, Binder H, Cold S, Gravgaard K, Knoop AS and Ditzel HJ: Novel circulating microRNA signature as a potential non-invasive multi-marker test in ER-positive early-stage breast cancer: A case control study. Mol Oncol 8: 874-883, 2014.

45. Rask L, Balslev E, Søkilde R, Høgdall E, Flyger H, Eriksen J and Litman T: Differential expression of miR-139, miR-486 and miR-21 in breast cancer patients sub-classified according to lymph node status. Cell Oncol (Dordr) 37: 215-227, 2014.

46. Ratert N, Meyer HA, Jung M, Lioudmer P, Mollenkopf HJ, Wagner I, Miller K, Kilic E, Erbersdobler A, Weikert S and Jung K: miRNA profiling identifies candidate mirnas for bladder cancer diagnosis and clinical outcome. J Mol Diagn 15: 695-705, 2013.

47. Cazzoli R, Buttitta F, Di Nicola M, Malatesta S, Marchetti A, Rom WN and Pass HI: microRNAs derived from circulating exosomes as noninvasive biomarkers for screening and diagnosing. J Thorac Oncol 8: 1156-1162, 2013.

48. Liu X, Xiong F, Wei X, Yang H and Zhou R: LAPTM4B-35, a novel tetratransmembrane protein and its PPRP motif play critical roles in proliferation and metastatic potential of hepatocellular carcinoma cells. Cancer Sci 100: 2335-2340, 2009.

49. Ather $\mathrm{MH}$ and Nazim SM: New and contemporary markers of prognosis in nonmuscle invasive urothelial cancer. Korean $\mathbf{J}$ Urol 56: 553-564, 2015.

50. Guo H, Hu X, Ge S, Qian G and Zhang J: Regulation of RAP1B by miR-139 suppresses human colorectal carcinoma cell proliferation. Int J Biochem Cell Biol 44: 1465-1472, 2012.

51. Stork PJ: Does rap1 deserve a bad rap? Trends Biochem Sci 28: $267-275,2003$. 
52. Zhang L, Dong Y, Zhu N, Tsoi H, Zhao Z, Wu CW, Wang K, Zheng S, Ng SS, Chan FK, et al: microRNA-139-5p exerts tumor suppressor function by targeting NOTCH1 in colorectal cancer. Mol Cancer 13: 124, 2014.

53. Mitrea DM, Yoon MK, Ou L and Kriwacki RW: Disorder-function relationships for the cell cycle regulatory proteins p21 and p27. Biol Chem 393: 259-274, 2012.

54. Song M, Yin Y, Zhang J, Zhang B, Bian Z, Quan C, Zhou L, $\mathrm{Hu}$ Y, Wang Q, Ni S, et al: MiR-139-5p inhibits migration and invasion of colorectal cancer by downregulating AMFR and NOTCH1. Protein Cell 5: 851-861, 2014.

55. Fang S, Ferrone M, Yang C, Jensen JP, Tiwari S and Weissman AM: The tumor autocrine motility factor receptor, gp78, is a ubiquitin protein ligase implicated in degradation from the endoplasmic reticulum. Proc Natl Acad Sci USA 98 14422-14427, 2001.

56. Wang L, Hou G, Xue L, Li J, Wei P and Xu P: Autocrine motility factor receptor signaling pathway promotes cell invasion via activation of ROCK-2 in esophageal squamous cell cancer cells. Cancer Invest 28: 993-1003, 2010.

57. Chiu CG, St-Pierre P, Nabi IR and Wiseman SM: Autocrine motility factor receptor: A clinical review. Expert Rev Anticancer Ther 8: 207-217, 2008.

58. Gu J, Chen Y, Huang H, Yin L, Xie Z and Zhang MQ: Gene module based regulator inference identifying miR-139 as a tumor suppressor in colorectal cancer. Mol Biosyst 10: 3249-3254, 2014

59. Au SL, Wong CC, Lee JM, Fan DN, Tsang FH, Ng IO and Wong CM: Enhancer of zeste homolog 2 epigenetically silences multiple tumor suppressor microRNAs to promote liver cancer metastasis. Hepatology 56: 622-631, 2012.

60. Wong CC, Wong CM, Tung EK, Man K and Ng IO: Rho-kinase 2 is frequently overexpressed in hepatocellular carcinoma and involved in tumor invasion. Hepatology 49: 1583-1594, 2009.

61. Qiu G, Lin Y, Zhang $\mathrm{H}$ and Wu D: miR-139-5p inhibits epithelial-mesenchymal transition, migration and invasion of hepatocellular carcinoma cells by targeting ZEB1 and ZEB2. Biochem Biophys Res Commun 463: 315-321, 2015.

62. Vandewalle C, Van Roy F and Berx G: The role of the ZEB family of transcription factors in development and disease. Cel Mol Life Sci 66: 773-787, 2009.

63. Gheldof A, Hulpiau P, van Roy F, De Craene B and Berx G: Evolutionary functional analysis and molecular regulation of the ZEB transcription factors. Cell Mol Life Sci 69: 2527-2541, 2012.

64. Zhang Y, Shen WL, Shi ML, Zhang LZ, Zhang Z, Li P, Xing LY, Luo FY, Sun Q, Zheng XF, et al: Involvement of aberrant miR-139/Jun feedback loop in human gastric cancer. Biochim Biophys Acta 1853: 481-488, 2015.

65. Guo L, Guo Y and Xiao S: Expression of tyrosine kinase Etk/Bmx and its relationship with AP-1- and NF-kappaB-associated proteins in hepatocellular carcinoma. Oncology 72: 410-416, 2007.

66. Yoon JH, Choi YJ and Lee SG: Ginsenoside Rh1 suppresses matrix metalloproteinase-1 expression through inhibition of activator protein-1 and mitogen-activated protein kinase signaling pathway in human hepatocellular carcinoma cells. Eur J Pharmacol 679: 24-33, 2012

67. Fan Q, He M, Deng X, Wu WK, Zhao L, Tang J, Wen G, Sun X and Liu Y: Derepression of c-Fos caused by microRNA-139 down-regulation contributes to the metastasis of human hepatocellular carcinoma. Cell Biochem Funct 31: 319-324, 2013.

68. Humbert PO, Verona R, Trimarchi JM, Rogers C, Dandapani S and Lees JA: E2f3 is critical for normal cellular proliferation. Gene Dev 14: 690-703, 2000

69. Krishnan K, Steptoe AL, Martin HC, Pattabiraman DR, Nones K, Waddell N, Mariasegaram M, Simpson PT, Lakhani SR, Vlassov A, et al: miR-139-5p is a regulator of metastatic pathways in breast cancer. RNA 19: 1767-1780, 2013.
70. Wagner RT, Xu X, Yi F, Merrill BJ and Cooney AJ: Canonical Wnt $/ \beta$-catenin regulation of liver receptor homolog-1 mediates pluripotency gene expression. Stem Cells 28: 1794-1804, 2010.

71. Wang S, Lan F, Huang L, Dong L, Zhu Z, Li Z, Xie Y and Fu J: Suppression of hLRH-1 mediated by a DNA vector-based RNA interference results in cell cycle arrest and induction of apoptosis in hepatocellular carcinoma cell BEL-7402. Biochem Biophys Res Commun 333: 917-924, 2005.

72. Chand AL, Herridge KA, Thompson EW and Clyne CD: The orphan nuclear receptor LRH-1 promotes breast cancer motility and invasion. Endocr Relat Cancer 17: 965-975, 2010.

73. Kothapalli D, Zhao L, Hawthorne EA, Cheng Y, Lee E, Pure E and Assoian RK: Hyaluronan and CD44 antagonize mitogen-dependent cyclin D1 expression in mesenchymal cells. J Cell Biol 176: 535-544, 2007.

74. Kaneko T, Saito H, Toya M, Satio T, Nakahara K and Hiroi M: Hyaluronic acid inhibits apoptosis in granulosa cells via CD44. J Assist Reprod Genet 17: 162-167, 2000.

75. Peluso JJ, Liu X, Gawkowska A, Lodde V and Wu CA: Progesterone inhibits apoptosis in part by PGRMC1-regulated gene expression. Mol Cell Endocrinol 320: 153-161, 2010.

76. Szczesna-Skorupa E and Kemper B: Progesterone receptor membrane component 1 inhibits the activity of drug-metabolizing cytochromes $\mathrm{P} 450$ and binds to cytochrome $\mathrm{p} 450$ reductase. Mol Pharmacol 79: 340-350, 2011.

77. Abe R: Angiogenesis in tumor growth and metastasis. Curr Pharm Des 14: 3779, 2008.

78. Maehara Y, Kabashima A, Koga T, Tokunaga E, Takeuchi H, Kakeji Y and Sugimachi K: Vascular invasion and potential for tumor angiogenesis and metastasis in gastric carcinoma. Surgery 128: 408-416, 2000.

79. Bao W, Fu HJ, Xie QS, Wang L, Zhang R, Guo ZY, Zhao J, Meng YL, Ren XL, Wang T, et al: HER2 interacts with CD44 to up-regulate CXCR4 via epigenetic silencing of microRNA-139 in gastric cancer cells. Gastroenterology 141: 2076-2087.e6, 2011.

80. Carlson RW, Anderson BO, Burstein HJ, Carter WB, Edge SB, Farrar WB, Goldstein LJ, Gradishar WJ, Hayes DF, Hudis CA, et al: Invasive breast cancer. J Natl Compr Canc Netw 5: 246-312, 2007.

81. Hua W, Sa KD, Zhang X, Jia LT, Zhao J, Yang AG, Zhang R, Fan $\mathrm{J}$ and Bian K: MicroRNA-139 suppresses proliferation in luminal type breast cancer cells by targeting Topoisomerase II alpha. Biochem Biophys Res Commun 463: 1077-1083, 2015.

82. Shimizu S, Narita $M$ and Tsujimoto Y: Bcl-2 family proteins regulate the release of apoptogenic cytochrome c by the mitochondrial channel VDAC. Nature 399: 483-487, 1999.

83. Bannerji R, Kitada S, Flinn IW, Pearson M, Young D, Reed JC and Byrd JC: Apoptotic-regulatory and complement-protecting protein expression in chronic lymphocytic leukemia: Relationship to in vivo rituximab resistance. J Clin Oncol 21: 1466-1471, 2003.

84. Hussain SR, Cheney CM, Johnson AJ, Lin TS, Grever MR, Caligiuri MA, Lucas DM and Byrd JC: Mcl-1 is a relevant therapeutic target in acute and chronic lymphoid malignancies: Down-regulation enhances rituximab-mediated apoptosis and complement-dependent cytotoxicity. Clin Cancer Res 13: 2144-2150, 2007

85. Kaji D, Miura Y and Takano T: Adjuvant trastuzumab in HER2-positive breast cancer. N Engl J Med 366: 663-664, 2012.

86. Chen X, Shi K, Wang Y, Song M, Zhou W, Tu H and Lin Z: Clinical value of integrated-signature miRNAs in colorectal cancer: miRNA expression profiling analysis and experimental validation. Oncotarget 6: 37544-37556, 2015.

87. Singh AK, Swarnalatha M and Kumar V: c-ETS1 facilitates G1/S-phase transition by up-regulating cyclin E and CDK2 genes and cooperates with hepatitis $\mathrm{B}$ virus $\mathrm{X}$ protein for their deregulation. J Biol Chem 286: 21961-21970, 2011. 